FACULDADE DE CIÊNCIAS ECONÔMICAS DA UFRGS
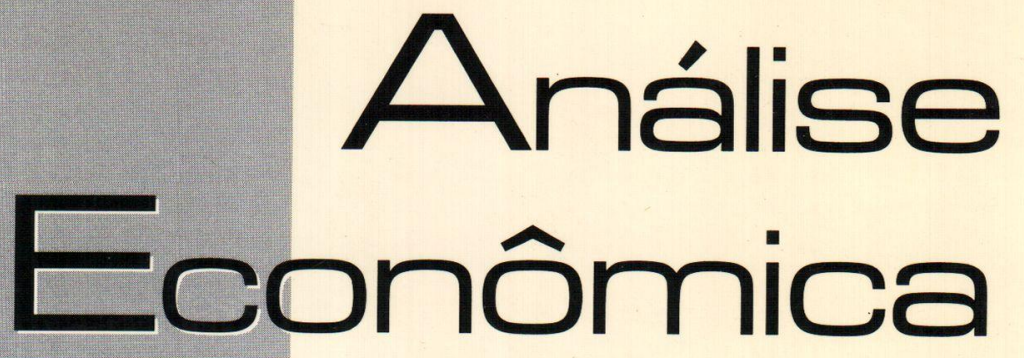

A CIÉNCIA ECONOMICA NA EUROPA E NOS Estados Unidos: PluRAlismo Versus MONISMO

ANTONio Maria da SiLveira

A EXPANSÃO DO COMERCIO MUNDIAL: IMPLICACOO ES SOBRE A HIPÓ TESE DE CONVERGENCIA

MANOEL BOSCO DE ALMEIDA

O SETOR AGRICOLA NA ÁREA DE LIVRE COMERCIO DAS AMÉRICAS: DESAFIOS DA INTEGRAÇÃO REGIONAL

PAULO D. WAQUIL.

PEQUENOS E MEDIOS FABRICANTES DE BENS DE CAPITAL FRENTE AS MUDANÇAS NA ECONOMIA BRASILEIRA

HOYEDO NUNES LINS

RISCOS NA ATIVIDADE BANCÁRIA EM CONTEXTO DE ESTABILIDADE DE PREÇOSE DE ALTA INFLAÇÃO

LUIS FERNANDO RODRIGUES DE Paula

O FIO DA NAVALHA DE HARROd EA RESPOSTA DA ESCOLA DE CAMBRIDGE MARIo AUGusto Bertella

A DINAMMICA FINANCEIRA INTERNACIONAL E A TENDENCIA Ã DOLARIZAÇÄO DAS ECONOMIAS LATINO-AMERICANAS

MARCOS ANTONIO MACEDO CinTRA

TEMPORALIDADE DA RIQUEZA - TEORIA DA DINAMMICA E FINANCEIRIZAÇÃO DO CAPITALISMO - RESENHA

Gentil Corazza

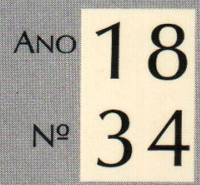


Universtode Federal do Rio Grande do Sul

Reitora: Prof ${ }^{a}$. Wrana Maria Panizzi

Faculdade de Crências Econômicas.

Diretora: Prof ${ }^{4}$. Otilia Beatriz Kroeff Carrion

Centro de Estudos e Pesquisas Econômicas

Diretor: Prof. Fernando Ferrari Filho

Departamento de Ciências Económicas

Chefe: Prof. Luiz Alberto Oliveira Ribeiro de Miranda

Departamento de Crências Contábeis e Atuariais

Chefe: Prof. João Marcos Leão da Rocha

Curso de Pós-Graduação em Economia

Coordenador: Prof Marcelo Savino Portugal

Curso de Pós-Graduação em Desenvolvimento Rurai

Coordenador: Prof Carlos Guilherme A. Mielitz Netto

Consel.ho Eomorial: Achyles B. Costa, Aray M. Feldens, Carlos A Crusius, Carlos G. A Mielitz Netto, Eduardo A. Maldonado Filho, Eduardo P. Ribeiro, Eugênio Lagemann, Fernando Ferrari Filho, Gentil Corazza, Jan A. Kregel, Marcelo S. Portugal, Nali J. Souza, Otília B. K Carrion, Paulo A. Spohr, Paulo D. Waquil, Pedro C. D. Fonseca, Philip Arestis, Roberto C. Moraes, Ronald Otto Hillbrecht, Stefano Florissi, Eleutério F. S. Prado (USP), Fernando H Barbosa (FGV/RJ), Gustavo Franco (PUC/RJ), João R. Sanson (UFSC), Joaquim P. Andrade (UnB), Juan H. Moldau (USP), Paul Davidson (Univ of Tennessee), Werner Baer (Univ. of Mlinois)

Comissāo Eoitonial: Eduardo Augusto Maldonado Filho, Fernando Ferrari Filho, Gentil Corazza, Marcelo Savino Portugal, Paulo Dabdab Waquil, Roberto Camps Moraes.

EdITor: Gentil Corazza

EdrTor Adjunto: Pedro Silveira Bandeira

Secretarus: Márcio Souza de Vargas

REVISĩo de teXtos: Vanete Ricacheski

Fundador: Prof. Antônio Carlos Santos Rosa

Os materiais publicados na revista Análise Econômica são da exclusiva responsabilidade dos autores. É permitida a reprodução total ou parcial dos trabalhos, desde que seja citada a fonte. Aceita-se permuta com revistas congêneres. Aceitam-se, também, livros para divulgação, elaboração de resenhas e recensões. Toda correspondência, material para publicação (vide normas na terceira capa), assinaturas e permutas devem ser dirigidos ao seguinte destinatário:

Prof. Genth Corazza

Revisia Anáxise Econômica - Av. João Pessoa, 52 CEP 90040-000 PORTO ALEGRE - RS, BRASIL

Telefones: (051) 316-3513 316-3440 - Fax: (051) 316-3990 rae@vortex.ufrgs.br

Análise Econômica

Ano $18, n^{\circ} 34$, setembro, 2000 - Porto Alegre

Faculdade de Ciências Econômicas, UFRGS, 2000

Periodicidade semestral, março e setembro

1. Teoria Econômica - Desenvolvimento Regional Economia Agrícola - Pesquisa Teórica e Aplicada -

Periódicos. I Brasil

Faculdade de Ciências Econômicas,

Universidade Federal do Rio Grande do Sul.

CDD 330.05

CDU $33(81)(05)$ 


\section{O setor agrícola na Área de Livre Comércio das Américas: desafios da integração regional}

Paulo D. Waquil

Resumo: $\mathrm{O}$ artigo analisa os desafios a serem enfrentados pelo setor agrícola dos países que formarão a ALCA. Inicialmente, apresenta os antecedentes e perspectivas do esquema de integração regional. Caracteriza então o setor agrícola na região, e revisa alguns estudos que buscam identificar os impactos da formação da área de livre comércio, em vista das assimetrias e distorções existentes, das possibilidades de polarização e de distribuição desigual dos benefícios e custos associados ao processo de integração.

Palavras-chave: Integração regional, ALCA, agricultura.

Abstract: The paper analyses the challenges that the agricultural sector in the countries that form the FTAA will face. First, it presents the arrangements and perspectives of the regional integration scheme. Then it characterizes the agricultural sector in the region, and reviews several studies which aim to identify the impacts of the formation of the free trade area, taking into consideration the existing asymmetries and distortions, the possibilities of polarization and unequal distribution of the benefits and costs associated with the process.

Key-words: Regional integration, FTAA, agriculture.

\section{Introdução}

Integrar significa unir, tornar inteiro, combinar partes em um todo. Integrar nações pode ser entendido como um processo de remoção de discriminação entre as diferentes nações envolvidas. Integrar pode ser visto como um processo mais amplo, um processo multidimensional de relacionamento e interdependência entre as nações, que requer uma base comum de valores e preferências, e a percepção dos benefícios da integração de forma que todos os participantes possam sustentar o processo.

Entretanto, a integração dos países em uma área de livre comércio envolve apenas a remoção de barreiras comerciais entre os países membros, eliminando tarifas, restrições quantitativas e outras barreiras aos fluxos comerciais, mas não regulamentando o comércio com os países não-membros. Uma

\footnotetext{
' Professor Adjunto do Departamento de Ciências Econômicas (DECON) e dos Programas de Pós-Graduação em Desenvolvimento Rural (PGDR), Agronegócios (PPGAN) e Economia (PPGE) da Universidade Federal do Rio Grande do Sul (UFRGS).
} 
área de livre comércio não estabelece tarifas externas comuns, não permite a livre mobilidade dos fatores de produção, e não envolve a harmonização de políticas macroeconômicas e setoriais.

A realização da Cúpula das Américas; em dezembro de 1994 em Miami, deu início ao processo de união das economias de 34 países das Américas do Norte, Central e do Sul, exceto Cuba, numa área de livre comércio, a ALCA Área de Livre Comércio das Américas. As negociações deverão ser concluídas até 2005 , quando o esquema de integração hemisférica será então implementado. A ALCA se insere no contexto atual de formação e de fortalecimento de blocos regionais, implicando a interconexão e a interdependência crescente entre as nações participantes. Desde já convém deixar claro que a ALCA, como uma área de livre comércio, envolve somente a integração comercial, e não um processo multidimensional, mais profundo, de integração entre as nações americanas.

A literatura econômica apresenta a possibilidade de benefícios e custos associados ao processo de integração. Os benefícios surgem como resultado da maior eficiência produtiva devido à especialização, economias de escala devido à concentração da produção, melhoria da posição de barganha nos mercados internacionais possibilitada pelo aumento do tamanho dos mercados integrados. Num nível mais aprofundado de integração, há também a possibilidade de benefícios resultantes da coordenação de políticas macroeconômicas e setoriais, e unificação dos objetivos, tais como o desenvolvimento econômico, pleno emprego e distribuição da renda. Por outro lado, os custos associados ao processo de integração resultam da necessidade de ajustes estruturais, do enfraquecimento das políticas nacionais (principalmente as políticas protecionistas), do deslocamento do papel do Estado, e da possibilidade de desvios de comércio.

Tanto os benefícios como os custos são distribuídos de forma diferenciada entre os diversos setores. Mesmo que os benefícios sejam maiores que os custos para os países envolvidos, pode haver perdas para determinados setores ou grupos de agentes. Faz-se necessário então um esquema de compensações, que pode envolver a realocação de recursos, desenvolvimento de infra-estrutura, auxílio a áreas menos desenvolvidas. O problema é que estas compensações raramente são realizadas. Macadar (1996) sugere que as propostas de acordos de livre comércio entre os blocos existentes atualmente, mais especificamente do MERCOSUL com o North American Free Trade Agreement (NAFTA) e com a União Européia (UE), comportam o risco de aprofundar ainda mais as assimetrias já existentes, à medida que os benefícios resultantes de tais acordos sejam menores que os custos para os países em desenvolvimento. 
É neste contexto que se insere o presente artigo. Há áreas de convergência, há benefícios associados ao processo, mas há também divergências, assimetrias, possibilidades de polarização, que devem ser vencidas para que as nações envolvidas dêem sustentação ao processo de integração. $O$ artigo analisa os desafios a serem enfrentados pelo setor agrícola dos países que formarão a ALCA. Poucos estudos têm sido realizados sobre os impactos da liberalização comercial entre os países norte, centro e sul-americanos, e particularmente sobre o setor agrícola na região. Este artigo vem contribuir no sentido de apresentar os antecedentes e perspectivas da ALCA, caracterizar o setor agrícola na região, e revisar estudos que buscam identificar os impactos da formação da área de livre comércio.

\section{A formação da ALCA, antecedentes e perspectivas}

O processo de integração numa área de livre comércio iniciou-se com a realização da Cúpula das Américas, em dezembro de 1994 em Miami. Naquela ocasião, os chefes de governo aprovaram a Declaração de Princípios e o Plano de Ação, segundo o qual as negociações deverão estar concluídas até 2005 . As negociações da ALCA deverão examinar o relacionamento entre diversas áreas. Para isto, foram formados 12 grupos de trabalho, com a meta de obter e organizar informações sobre as relações comerciais e examinar as assimetrias e possibilidades de compatibilização de políticas entre os países que participam do processo.

Desde a Cúpula de Miami, os Ministros de Comércio reuniram-se quatro vezes para executar o plano de ação da ALCA, apresentar relatórios dos grupos de trabalho e definir o cronograma para as negociações subseqüentes: em junho de 1995 em Denver, EUA; em março de 1996 em Cartagena das Índias, Colômbia; em maio de 1997 em Belo Horizonte; e em março de 1998 em San Jose, Costa Rica. Aparentemente, estas reuniões compuseram a parte mais fácil das negociações, preparando para a segunda Cúpula dos chefes das nações participantes, ocorrida em Santiago, Chile, em abril de 1998.

Durante as negociações, os grupos de trabalho foram transformados em nove grupos de negociação: (1) acesso a mercados, presidido pela Colômbia; (2) investimentos, presidido pela Costa Rica; (3) serviços, presidido pela Nicarágua; (4) compras governamentais, presidido pelos Estados Unidos; (5) solução de controvérsias, presidido pelo Chile; (6) agricultura, presidido pela Argentina; (7) direitos de propriedade intelectual, presidido pela Venezuela; (8) subsídios, antidumping e medidas compensatórias, presidido pelo Brasil; e (9) políticas de concorrência, presidido pelo Peru. A atribuição da presidência 
de 2 grupos de trabalho (agricultura e subsídios, anti-dumping e medidas compensatórias) aos países do MERCOSUL é um fato de grande relevância, em vista da importância agrícola e agroindustrial da região (Taglialegna, Jank, Miranda e Ribeiro, 1998).

As áreas de convergência, reafirmadas durante as reuniões ministeriais, incluem: o mecanismo de consenso como princípio fundamental na tomada de decisões; a necessidade de compatibilidade com as normas da OMC; a possibilidade de negociar e aderir à ALCA individualmente ou como membro de um acordo sub-regional; e a atenção especial às condições, necessidades e oportunidades das menores economias da região. Por outro lado, ainda existem várias áreas de divergência, ainda existem diversos aspectos pendentes nas negociações. Estas controvérsias envolvem as negociações predominantemente relativas ao acesso a mercados, incluindo ou não itens como comércio de serviços, proteção da propriedade intelectual, tratamento de investimento estrangeiro, políticas de competição, meio ambiente e mercado de trabalho. Por ocasião da quinta reunião ministerial, ocorrida em novembro de 1999 em Toronto, Canadá, foram expostas, ainda mais, as controvérsias existentes. No centro das discussões, estavam as preocupações com os subsídios agrícolas e as escaladas tarifárias.

Além disto, um dos maiores desafios para a criação da ALCA reside no fato de que os incentivos a participar são heterogêneos, devido às assimetrias existentes entre os países norte, centro e sul-americanos. Os Estados Unidos são responsáveis por mais de $3 / 4$ do $\mathrm{PIB}$ da região e respondem por uma parcela dominante do comércio exterior. São também a principal fonte de investimentos e tecnologia para a maioria dos países participantes. Por outro lado, existem várias economias pequenas, com menores níveis de desenvolvimento, bastante dependentes dos mercados externos, capacidade produtiva limitada e pouca diversificação.

A formação da ALCA surge como uma experiência pioneira de integração entre países desenvolvidos e em desenvolvimento. Assim, diversos países percebem os benefícios potenciais com alguma ambigüidade, isto é, têm dúvidas quanto ao balanço entre benefícios e custos do processo. Não existe ainda uma base comum de valores e preferências, não existe ainda a percepção dos benefícios da integração de forma que todos os participantes possam sustentar o processo. Desta forma, o tratamento destas assimetrias ao longo do processo de negociação é um dos principais desafios para a formação da área de livre comércio.

Alguns estudos têm sido elaborados nestes últimos anos, analisando as perspectivas da formação da ALCA. Panagariya (1996) apresenta a ALCA como um empreendimento inovador e ambicioso, no sentido de formar um 
bloco do tipo Norte-Sul, diferenciando dos já existentes blocos dos tipos Norte-Norte e Sul-Sul, e integrando então países com profundas diferenças econômicas, sociais, culturais e políticas. $\mathrm{O}$ autor cita como possíveis vantagens deste processo: o melhor acesso dos países latino-americanos a mercados desenvolvidos e sua consolidação onde o acesso já era facilitado; a proteção dos países menores contra medidas antidumping e salvaguardas; e a garantia do livre comércio na região, dificultando o retrocesso às ações protecionistas. Por outro lado, indica como preocupações: a deterioração dos termos de troca para os países latino-americanos, já que possuem tarifas iniciais mais elevadas e são mais vulneráveis à abertura; efeitos adversos na distribuição de renda dos países do Norte, devido à concorrência com a mão-de-obra mais barata dos países do Sul, situação que poderia gerar medidas mais restritivas, como rígidas regras de origem, desfazendo a lógica do livre comércio; por fim, o autor aponta que os ganhos para os países latino-americanos podem estar mais associados ao acesso facilitado aos mercados dos demais parceiros latino-americanos do que propriamente aos mercados dos Estados Unidos e Canadá, sugerindo então que os benefícios da formação da ALCA podem estar sendo superestimados.

Araújo (1998) ilustra as assimetrias existentes entre os países que formarão a ALCA. Indica que "a população norte-americana corresponde a 34,9\% do hemisfério, mas gera $76,2 \%$ do PIB e $72,7 \%$ dos bens industriais; a população brasileira é cinco vezes superior à canadense, mas o tamanho do mercado interno é similar nos dois países; o México tem três vezes mais habitantes que a Argentina, mas sua produção doméstica aparenta ser inferior, devido às disparidades monetárias existentes entre as duas economias. Dentre os 34 países membros do bloco, os quatro maiores contribuem com $93,2 \%$ da produção industrial" (p.18-19). O autor aponta que o projeto de formação da ALCA somente será capaz de harmonizar os interesses assimétricos se os países grandes da região cumprirem seu papel de fontes geradoras de crescimento. Sugere que "não basta abolir barreiras comerciais, é preciso também assegurar a continuidade dos fluxos de investimentos diretos e de transferência de tecnologia que, de fato, são os únicos mecanismos capazes de corrigir assimetrias entre os parceiros comerciais" (p.24).

Com base nos argumentos desenvolvidos ao longo de seu trabalho, Araújo (1998) apresenta uma lista de riscos e oportunidades que o projeto da ALCA pode oferecer à economia brasileira. "Os riscos são advindos de quatro fonteś principais: o atraso tecnológico de certos segmentos da indústria nacional, a inconsistência das políticas governamentais, a heterogeneidade dos países que participam do projeto, e o formato atual da agenda de negociações. As oportunidades estão localizadas em quatro áreas: melhoria da qualidade do gasto 
público brasileiro, fortalecimento do marco regulador das condições de concorrência, novas funções a serem cumpridas pelo governo e o setor privado no plano internacional, e a recuperação da competitividade da indústria nacional" (p.45). O autor conclui que as ameaças não decorrem da área de livre comércio, mas da existência de uma superpotência no apogeu de sua capacidade econômica, militar e tecnológica. Por fim, indica que o projeto de integração hemisférica interessa à sociedade brasileira, mas que seus resultados dependem de que o governo cumpra a tarefa de defesa dos interesses do país.

Gonçalves (1998) apresenta que, além do objetivo de criar melhores condições de acessos a mercados, a ALCA tem como meta a constituição de um foro de negociação dos conflitos nas áreas de comércio de bens e serviços, investimento e propriedade intelectual entre os Estados Unidos e os demais países do hemisfério ocidental. $\mathrm{O}$ autor indica que, na ótica dos países latinoamericanos, a principal motivação para a formação do bloco é a eliminação de restrições comerciais e o conseqüente tratamento preferencial de acesso ao mercado norte-americano, assim como a obtenção de ganhos resultantes de eventuais fluxos de investimentos na região. Por outro lado, na ótica dos norteamericanos, a principal motivação está na expansão das oportunidades de exportação e negócios, e na consolidação da influência dos Estados Unidos na região.

Analisando o processo de integração assimétrico e acelerado, Coutinho e Furtado (1998) também discutem os riscos e oportunidades associados à formação da ALCA. Indicam que os ganhos e os custos dificilmente poderão ser distribuídos de forma homogênea, já que o processo envolve atores tão desiguais, e apresentam uma perspectiva de ganhos limitados e de riscos elevados para a economia brasileira.

Os autores apontam que "a ALCA não é o único eixo da política comercial norte-americana e os Estados Unidos desenvolvem, paralelamente ao seu próprio projeto de constituição da ALCA, os seus dois outros vetores de integração, um voltado para a Europa e o outro para a Ásia. Em ambos os casos, os países-alvo da estratégia procuram adequar o cronograma e o conteúdo das negociações aos seus próprios interesses. É ilusório imaginar que os possíveis ganhos comerciais brasileiros no mercado americano possam vir a ser estáveis ou duradouros" (p.48). Concluem que, à semelhança da política desenvolvida pelos Estados Unidos, a opção mais construtiva e mais vantajosa para o Brasil (e para o MERCOSUL) é a de perseguir simultaneamente uma política equilibrada em três eixos de integração: com o NAFTA, com a UE e com o Sistema Asiático.

Coordenando o estudo comparativo dos ganhos da integração, que considerou dez setores produtivos, Pereira (1997) simula diferentes cenários de 
integração, estima taxas de crescimento econômico e dos fluxos comerciais. Conclui que o acordo entre o MERCOSUL e a UE geraria um crescimento de $5,05 \%$ na economia brasileira e seria mais vantajoso para o Brasil do que a formação da ALCA que resultaria em um crescimento de apenas $2,08 \%$. Nas duas hipóteses, as exportações brasileiras sofreriam mudanças: o acordo com a UE reforçaria o perfil do Brasil como fornecedor de produtos agropecuários, enquanto a criação da ALCA elevaria as exportações brasileiras de produtos manufaturados para os Estados Unidos e Canadá. Entretanto, a autora também indica que a melhor opção é priorizar as negociações multilaterais, já que o país atende a uma diversidade de mercados e a liberalização para um lado ou outro levaria a uma mudança na orientação do comércio exterior do país.

Carvalho e Parente (1999) apresentam estimativas dos impactos da ALCA sobre os fluxos comerciais brasileiros, utilizando um modelo de equilíbrio parcial. Enfatizam que os países latino-americanos podem ter um alto custo de ajustamento à liberalização, mas prosseguem com as negociações por causa dos benefícios futuros que serão proporcionados pelo acesso a novos mercados, podendo viabilizar o crescimento das economias envolvidas. Estimam que "se a ALCA tiver como implicação direta a eliminação total e imediata das alíquotas incidentes sobre o universo de produtos transacionados no continente, as exportações brasileiras com destino à ALCA sofreriam um incremento da ordem de 7\%, ou seja, US\$ 1,5 bilhão, enquanto as importações provenientes da ALCA registrariam um aumento de aproximadamente $18 \%$, o que corresponde a US $\$ 4,3$ bilhões" (p.46). Concluem que a explicação destes resultados deve-se aos fatos de que boa parte dos ganhos para o Brasil trazidos pela liberalização comercial já foram obtidos com a formação do MERCOSUL e que a participação dos Estados Unidos no bloco reduz os ganhos dos demais parceiros, visto se tratar da maior potência mundial e o país com maiores ganhos de competitividade.

Averbug (1999) também apresenta os antecedentes da formação da ALCA e revisa os trabalhos de diversos autores, analisando as controvérsias em torno da integração hemisférica. Sintetiza que há um relativo consenso no Brasil: a consolidação da ALCA tende a trazer mais desvantagens do que vantagens para o país se for feita isoladamente e de forma assimétrica e precipitada. Sugere, então, que a negociação de um acordo do MERCOSUL com a UE deve ser feita paralelamente à ALCA, fato que poderia aumentar o poder de barganha do MERCOSUL e representar maiores oportunidades comerciais para o bloco.

Assim, com a percepção dos possiveis benefícios e custos associados ao processo de integração comercial, com o entendimento das assimetrias existentes e suas implicações para a distribuição destes benefícios e custos, passa-se à próxima seção, para a caracterização do setor agrícola no bloco e uma revisão dos impactos trazidos pelo processo para este setor nos países membros. 


\section{O setor agrícola nas Américas.}

O setor agrícola é de grande importância nos países que formarão a ALCA, tendo em vista sua participação na geração de renda, de emprego e de divisas. Apesar de a região gerar grandes excedentes exportáveis para as demais regiões do mundo, a implementação da área de livre comércio certamente afetará também os fluxos intra-regionais. Estes impactos deverão ocorrer em vista das diferentes aptidões agrícolas dos países (resultantes de diferenças edafoclimáticas), assim como das assimetrias existentes no setor agrícola (dotação de recursos produtivos, tecnologia, políticas diferenciadas para o setor, distorções nos mercados).

As tabelas a seguir ilustram algumas características dos principais países que formarão o bloco. Tendo em vista o interesse do presente artigo de discutir os impactos da formação da ALCA, os países estão agrupados conforme os atuais esquemas de integração regional (basicamente destacando o MERCOSUL e o NAFTA). Todas as tabelas apresentam dados médios para um período de três anos (1996-1998), visando evitar informações viesadas causadas por um ano atípico em determinada região.

A tabela 1 apresenta os dados referentes à população total e agrícola ${ }^{2}$, assim como a área ocupada com atividades de produção agrícola. Na ALCA como um todo, a população agrícola corresponde a $14,83 \%$ da população total. Existem, no entanto, grandes assimetrias. No Brasil, a população agrícola atinge quase 30 milhões de habitantes, correspondendo a $18,16 \%$ da população total do país. Paraguai e Bolívia são países que apresentam uma proporção bem mais elevada da população agrícola, superior a $40 \%$ da população total. Por outro lado, Canadá e Estados Unidos têm população agrícola inferior a 3\% da população total. Estas assimetrias podem ser ilustradas também pelas diferenças na relação entre a população agrícola e a área agrícola. Novamente, o Brasil aparece numa situação intermediária, assim como o Chile e o México. Nos países da América Central esta relação é a mais elevada, indicando o uso mais intensivo de mão-de-obra nas atividades agrícolas. No outro extremo, estão a Argentina, Uruguai, Canadá e Estados Unidos, indicando a utilização menos intensiva de mão-de-obra, em vista das atividades desenvolvidas (p.ex., pecuária extensiva) ou do alto grau de mecanização.

${ }^{2}$ Como neste trabalho o foco é o setor agrícola, não o meio rural, optou-se por apresentar a população agrícola, em vez da população rural Em diversos países, há uma diferença substancial entre as duas variáveis, já que uma parcela significativa da população rural exerce atividades não-agrícolas. 
O consumo de fertilizantes e a utilização de tratores na agricultura são ilustrados na tabela 2. Da mesma forma, há grandes assimetrias no emprego destes fatores de produção quando são comparados os valores por unidade de área agrícola. O Brasil ainda permanece numa situação intermediária, com um consumo de fertilizantes de 19,78 toneladas e 3,22 tratores por 1.000 ha, enquanto outros países sul-americanos (p.ex., Paraguai e Bolívia) mostram níveis substancialmente inferiores e países norte -americanos mostram níveis bem mais elevados. Comparando os blocos atualmente formados, o uso de fertilizantes e de tratores por unidade de área agrícola nos países do NAFTA é mais de três vezes superior aos valores apresentados nos países do MERCOSUL.

Tais assimetrias indicam disparidades tecnológicas entre os países da região, já apontando para os riscos associados ao processo de integração. Por outro lado, também é importante atentar para a participação da ALCA no mundo: a região responde por $13,49 \%$ da população mundial, mas apenas $4,56 \%$ da população agrícola. Os países que formarão a ALCA compreendem $25,28 \%$ da área agrícola mundial, $24,47 \%$ do consumo de fertilizantes e $26,68 \%$ dos tratores. Desta forma, a agricultura na região caracteriza-se pelo uso menos intensivo de mão-de-obra, mas mais intensivo em insumos "modernos" do que o resto do mundo.

Tabela 1: População total e agrícola e área agrícola nos países da ALCA (médias de 1996-1998)

\begin{tabular}{|c|c|c|c|c|c|}
\hline Paises/regiôes & $\begin{array}{c}\text { População } \\
\text { total } \\
\text { Imil habitantes) }\end{array}$ & $\begin{array}{c}\text { População } \\
\text { cgricola } \\
\text { (mil habitantes) }\end{array}$ & $\begin{array}{l}\text { \&População } \\
\text { agrícola / total }\end{array}$ & $\begin{array}{c}\text { Área agrícola } \\
\text { (mil hal }\end{array}$ & $\begin{array}{l}\text { Pop.agricola / } \\
\text { Área agricola } \\
\text { (hab./mil hal }\end{array}$ \\
\hline Argentina & 35.67 & 4.038 & $11,32 \%$ & 169.200 & 23,87 \\
\hline Brasil & 163695 & 29722 & $18,16 \%$ & 250.300 & 118,74 \\
\hline Paraguai & 5089 & 2151 & $42,26 \%$ & 23985 & 89,67 \\
\hline Uruguai & 3.266 & 370 & $11,34 \%$ & 14.826 & 24,98 \\
\hline Total MERCOSUL & 207.721 & 36.281 & $17,47 \%$ & 458.311 & 79,16 \\
\hline Ghile & 14623 & 2374 & $16,23 \%$ & 15.224 & 155,93 \\
\hline Bolivia & 7.775 & 3.378 & $43,45 \%$ & 35.904 & 94,09 \\
\hline Total MERC Expandido & 230.119 & 42.033 & $18,27 \%$ & 509.439 & 82,51 \\
\hline Outros América do Sul & 100.382 & 22.961 & $22,87 \%$ & 107.915 & 212,77 \\
\hline Total América do Sul & 330.501 & 64.994 & $19,67 \%$ & 617.354 & 105,28 \\
\hline América Central & 69.935 & 22.008 & $31,47 \%$ & 35.283 & 623,76 \\
\hline Conadá & 30.256 & 860 & $2,84 \%$ & 74700 & 11,52 \\
\hline Estados Unidos & 271746 & 6.617 & $2,44 \%$ & 418.250 & 15,82 \\
\hline México & 94.276 & 24007 & $25,46 \%$ & 107.200 & 223,95 \\
\hline Total América do Norte & 396.279 & 31.485 & $7,95 \%$ & 600.150 & 52,46 \\
\hline Total ALCA & 785.647 & 116.547 & $14,83 \%$ & 1.247 .440 & 93,43 \\
\hline Total Mundo & 5.823 .023 & 2.553 .651 & $43,85 \%$ & 4.935 .101 & 517,45 \\
\hline \% MERCOSLLL / Mundo & $3,57 \%$ & $1,42 \%$ & & $9,29 \%$ & \\
\hline \% ALCA / Mundo & $13,49 \%$ & $4,56 \%$ & & $25,28 \%$ & \\
\hline
\end{tabular}

Fonte: FAO. 
Tabela 2: Consumo de fertilizantes e tratores nos países da ALCA (médias de 19961998)

\begin{tabular}{|c|c|c|c|c|}
\hline Páses/regiōes & $\begin{array}{l}\text { Consumo de } \\
\text { fertilizontes (ton) }\end{array}$ & $\begin{array}{l}\text { Fertilizantes / Área } \\
\text { agricola Iton } / 1000 \\
\therefore \quad \text { hal }\end{array}$ & Tratores (unidades) & $\begin{array}{c}\text { Tratores / Área } \\
\text { agrícolo } \\
\text { (unid. } / 1000 \text { ha) }\end{array}$ \\
\hline Argentina & 736.433 & 4,35 & 280.000 & 1,65 \\
\hline Brasil & 4.950 .336 & 19,78 & 804.914 & 3,22 \\
\hline Paraguai & 30000 & 1,25 & 16.500 & 0,69 \\
\hline Uruguai & 316.300 & 7,84 & 33.000 & 2,23 \\
\hline Total MERCOSUL & 5.833 .070 & 12,73 & 1.134 .414 & 2,48 \\
\hline Chile & 421667 & 27,70 & 50.658 & 3,33 \\
\hline Bolivia & 9.489 & 0,26 & 5.667 & 0,16 \\
\hline Totdl MERC Expandido & 6.264 .225 & 12,30 & 1.190 .739 & 2,34 \\
\hline Outros América do Sul & 1.151 .186 & 10,67 & 93.480 & 0,87 \\
\hline Total América do Sul & 7.415 .411 & 12,01 & 1.284 .219 & 2,08 \\
\hline América Central & 1.006 .530 & 28,53 & 123.798 & 3,51 \\
\hline Conadá & 2.672 .542 & 35,78 & 711335 & 9,52 \\
\hline Estados Unidos & 20.184 .332 & 48,26 & 4.800 .000 & 11,48 \\
\hline México & 1.504 .500 & 14,03 & 172.000 & 1,60 \\
\hline Total América do Norte & 24.361 .374 & 40,59 & 5.683 .335 & 9,47 \\
\hline Total ALCA & 32.783 .315 & 26,28 & 7.013 .564 & 5,62 \\
\hline Total Mundo & 133.985 .848 & 27,15 & 26.285 .794 & 5,33 \\
\hline \% MERCOSUL / Mundo & $4,35 \%$ & & $4,32 \%$ & \\
\hline$\%$ ALCA / Mundo & $24,47 \%$ & & $26,68 \%$ & \\
\hline
\end{tabular}

Fonte: FAO.

A tabela 3 apresenta os níveis de produção agrícola por grupos de produtos, medidos em mil toneladas. Os países da ALCA têm uma grande participação na produção mundial de oleaginosas e café (respectivamente, 63,15\% e $57,35 \%$ ). Têm uma participação ainda elevada na produção de açúcar e carnes (acima de 30\%), e no caso dos cereais e leite, a participação dos países da ALCA é semelhante à participação na área agrícola (em torno de $25 \%$ ). Somente a produção de frutas e verduras na ALCA (17,98\% da produção mundial) é menor que a proporção da área agrícola mundial.

Os saldos comerciais gerados podem ser verificados na tabela 4 , pelas diferenças entre as quantidades exportadas e importadas. A ALCA aparece como um bloco que gera grandes excedentes, com exceção do leite. Tais excedentes equivalem a $37,44 \%$ da produção de café, e superam $15 \%$ da produção de açúcar, cereais e oleaginosas.

O Brasil tem grande importância neste cenário, como o maior produtor de açúcar e café; o segundo maior produtor de carnes, frutas e verduras, leite, 
e oleaginosas; e o terceiro maior produtor de cereais entre os países da ALCA. O país apresenta saldos positivos (exportações maiores que importações), exceto nos casos de cereais e leite. Entretanto, os Estados Unidos se destacam como o maior produtor agrícola do bloco, com mais da metade da produção continental de carnes, cereais, leite e oleaginosas. A produção de carnes, leite e oleaginosas nos Estados Unidos chega a ser quase três vezes superior à produção brasileira, e a produção de cereais é praticamente sete vezes maior que a produção brasileira. Assim, os riscos associados ao processo de integração não são devidos apenas às assimetrias na dotação de recursos e utilização de tecnologia, mas também devidos às assimetrias no tamanho dos mercados na região.

Tabela 3: Produção agrícola nos países da ALCA (médias de 1996-1998)

\begin{tabular}{|c|c|c|c|c|c|c|c|}
\hline Países/regiōes & $\begin{array}{l}\text { Açúcar } \\
\text { (mil ton.) }\end{array}$ & $\begin{array}{c}\text { Café } \\
\text { (mil ton.) }\end{array}$ & $\begin{array}{l}\text { Carnes } \\
\text { Imil ton.| }\end{array}$ & $\begin{array}{l}\text { Cereais } \\
\text { Imil ton.) }\end{array}$ & $\begin{array}{l}\text { Frutas e } \\
\text { Verduras } \\
\text { (mil ton.) }\end{array}$ & $\begin{array}{l}\text { Leite } \\
\text { Imil ton.) }\end{array}$ & $\begin{array}{c}\text { Oleaginosas } \\
\text { (mil ton.) }\end{array}$ \\
\hline Argentino & 1.743 & 0 & 3.674 & 35.101 & 10.339 & 9.621 & 21.476 \\
\hline Brasil & 18.734 & 1.498 & 12.405 & 45100 & 42.569 & 21.716 & 35.23 \\
\hline Paraguai & 136 & 5 & 394 & 1.475 & 790 & 444 & 3.57 \\
\hline Uruguai & 17 & 0 & 594 & 2.153 & 722 & 1.384 & 7 \\
\hline Total MERCOSUL & 20.629 & 1.503 & 17.066 & 83.829 & 54.420 & 33.166 & 60.349 \\
\hline Chile & 450 & 0 & 845 & 2991 & 6.186 & 2094 & 22 \\
\hline Bolivia & 392 & 23 & 379 & 1.186 & 1.468 & 245 & 1.200 \\
\hline Total MERC. Expandido & 21.472 & 1.526 & 18.290 & 88.007 & 62.074 & 35.505 & 61.572 \\
\hline Outros América do Sul & 4.052 & 919 & 3.569 & 10.854 & 23.504 & 9.850 & 1.135 \\
\hline Total América do Sul & 25.524 & 2.445 & 21.860 & 98.861 & 85.578 & 45.355 & 62.706 \\
\hline América Central & 8.133 & 862 & 1.645 & 5.291 & 15.437 & 3.827 & 530 \\
\hline Canadá & 121 & 0 & 3.507 & 50.617 & 2892 & 8.213 & 6.297 \\
\hline Estados Unidos & 7.401 & 3 & 35.980 & 341.578 & 65568 & 71.899 & 89.49 \\
\hline México & 4.901 & 326 & 4.106 & 28.775 & 20.422 & 8.641 & 55 \\
\hline Total América do Norte & 12.423 & 329 & 43.593 & 420.970 & 88.883 & 88.754 & 96.339 \\
\hline Totol ALCA & 42.314 & 3.616 & 66.887 & 524.608 & 188.020 & 137.287 & 159.567 \\
\hline Total Mundo & 129.711 & 6.306 & 221.265 & 2.081 .048 & 1.045 .970 & 554.182 & 252.661 \\
\hline$\%$ MERCOSUL / Mundo & $15,90 \%$ & $23,84 \%$ & $7,71 \%$ & $4,03 \%$ & $5,20 \%$ & $5,98 \%$ & $23,89 \%$ \\
\hline$\% \mathrm{ALCA} / \mathrm{Mundo}$ & $32,62 \%$ & $57,35 \%$ & $30,23 \%$ & $25,21 \%$ & $17,98 \%$ & $24,77 \%$ & $63,15 \%$ \\
\hline
\end{tabular}

Fonte: FAO 
Tabela 4: Exportações menos importações agrícolas nos países da ALCA (médias de 1996-1998)

\begin{tabular}{|c|c|c|c|c|c|c|c|}
\hline Países/regiões & $\begin{array}{l}\text { Açúcar } \\
\text { Imil ton!) }\end{array}$ & $\begin{array}{l}\text { Café } \\
\text { (mil ton. }\end{array}$ & $\begin{array}{l}\text { Carnes } \\
\text { Imil ton.] }\end{array}$ & $\begin{array}{l}\text { Cereais } \\
\text { (mil ton.) }\end{array}$ & $\begin{array}{l}\text { Frutas e } \\
\text { Verduras } \\
\text { Imil ton.l }\end{array}$ & $\begin{array}{l}\text { Leite } \\
\text { (mil ton.) }\end{array}$ & $\begin{array}{l}\text { Oleaginosas } \\
\text { (mil ton. }\end{array}$ \\
\hline Argentina & 133 & -39 & 255 & 19.535 & 1398 & 684 & 10.889 \\
\hline Brasil & 6.919 & 881 & 718 & -8.482 & 298 & -1705 & 10.555 \\
\hline Paraguai & 8 & -1 & 29 & 208 & -26 & -42 & 525 \\
\hline Uruguai & -95 & -2 & 219 & 771 & 40 & 408 & 13 \\
\hline Total MERCOSUL & 6.965 & 839 & 1.223 & 12.032 & 1.711 & -673 & 21.983 \\
\hline Chile & -232 & -13 & -64 & $-1,306$ & 1.749 & -95 & -338 \\
\hline Bolivia & 73 & 6 & 2 & -196 & 4 & -61 & 445 \\
\hline Total MERC Expandido & 6.806 & 832 & 1.161 & 10.529 & 3.464 & -830 & 22.090 \\
\hline Outros América do Sul & 459 & 785 & -62 & -8.328 & 5.338 & -1.193 & -1.263 \\
\hline Total América do Sul & 7.265 & 1.618 & 1.099 & 2.200 & 8.803 & -2.023 & 20.826 \\
\hline América Central & 5.307 & 704 & -188 & -6.206 & 4.961 & -1.149 & -882 \\
\hline Conadá & -1.090 & -142 & 395 & 20.884 & -1.037 & 404 & 593 \\
\hline Estados Unidos & -2.417 & -1047 & 2539 & 77.799 & -4.234 & 414 & 5.61 \\
\hline México & 732 & 226 & -532 & .9 .415 & 3.618 & -1.957 & -193 \\
\hline Total América do Norte & -2.775 & .963 & 2.402 & 89.268 & -1.653 & -1.139 & 6.012 \\
\hline Totol ALCA & 6.458 & 1.354 & 3.349 & 86.720 & 12.188 & -4.098 & 26.198 \\
\hline
\end{tabular}

Fonte: FAO.

Por outro lado, há também a possibilidade de ganhos, associados às oportunidades que surgem em vista de alguma complementaridade existente na região. Os Estados Unidos e Canadá são países importadores de açúcar, café, frutas e verduras, ao passo que o Brasil, Chile e México são importadores de cereais e leite. Estas necessidades de importação são supridas, em sua maior parte, por fluxos intra-regionais. Com o estabelecimento de uma área de livre comércio e a conseqüente eliminação de barreiras ao comércio na região, estes fluxos deverão ser facilitados, trazendo assim maiores benefícios para os países membros. Contudo, estes ganhos não são distribuídos igualmente. No caso do Brasil, os ganhos tendem a se concentrar nàs mãos dos produtores/exportadores de açúcar, café, frutas e verduras, enquanto as perdas tendem a ocorrer principalmente para os produtores de cereais e leite, ou seja, aqueles produtos que sofrerão com a competição dos produtos importados.

Por fim, a tabela 5 mostra que, entre todos os países (ou regiões) considerados neste artigo, somente o México tem balanço negativo no setor agríco1a. Os Estados Unidos apresentam o maior saldo (mais de US\$ 21 bilhões), seguido pela Argentina (quase US\$ 10 bilhões), Brasil (quase US\$ 9 bilhões) e Canadá (quase US\$ 5 bilhões). Os países que formarão a ALCA têm um saldo total de quase US $\$ 50$ bilhões, o que ilustra a magnitude dos excedentes agrícolas 
gerados na região. Os países do hemisfério ocidental participam, em conjunto, $\operatorname{com} 28,39 \%$ das exportações mundiais de produtos agrícolas, e apenas $16,99 \%$ das importações.

Tabela 5: Exportações, importações e saldo comercial de produtos agrícolas nos países da ALCA (médias de 1996-1998)

\begin{tabular}{lrrr}
\hline \multicolumn{1}{c}{ Países/regiôes } & \multicolumn{1}{c}{$\begin{array}{c}\text { Exportaçóes } \\
\text { (mil US\$) }\end{array}$} & $\begin{array}{c}\text { Importações } \\
\text { (mil US\$) }\end{array}$ & \multicolumn{1}{c}{$\begin{array}{c}\text { Saldo } \\
\text { (mil US\$) }\end{array}$} \\
\hline Argentina & 11.491 .939 & 1.567 .248 & 9.924 .691 \\
Brasil & 15.175 .064 & 6.228 .308 & 8.946 .756 \\
Paraguai & 743.451 & 672.207 & 71.244 \\
Uruguai & 1.262 .942 & 428.865 & 834.077 \\
\hline Total MERCOSUL & 28.673 .396 & 8.896 .628 & 19.776 .768 \\
\hline \hline Chile & 2.643 .005 & 1.292 .502 & 1.350 .503 \\
Bolívia & 382.794 & 171.584 & 211.210 \\
\hline Total MERCExpandido & 31.699 .195 & 10.360 .714 & 21.338 .481 \\
\hline \hline Outros América do Sul & 6.893 .507 & 5.482 .216 & 1.411 .291 \\
\hline Total América do Sul & 38.592 .702 & 15.842 .930 & 22.749 .772 \\
\hline \hline América Central & 7.520 .606 & 5.724 .856 & 1.795 .749 \\
\hline \hline Canadá & 15.095 .923 & 10.294 .573 & 4.801 .350 \\
Estados Unidos & 62.050 .824 & 40.275 .024 & 21.775 .800 \\
México & 6.259 .182 & 7.938 .342 & -1.679 .160 \\
\hline Total América do Norte & 83.405 .929 & 58.507 .939 & 24.897 .989 \\
\hline \hline Total ALCA & 128.621 .978 & 79.455 .834 & 49.166 .143 \\
\hline \hline Total Mundo & 452.996 .351 & 467.698 .602 & -14.702 .252 \\
\hline \hline \% MERCOSUL / Mundo & $6,33 \%$ & $1,90 \%$ & \\
\% ALCA / Mundo & $28,39 \%$ & $16,99 \%$ & \\
\hline
\end{tabular}

Fonte: FAO

Todas as informações acima ilustram a importância do setor agrícola nas discussões a respeito da formação da área de livre comércio, envolvendo temas como as assimetrias tecnológicas existentes, os excedentes gerados na região, as distorções resultantes da implementação de políticas domésticas de apoio ao setor (principalmente subsídios) ${ }^{3}$, a necessidade de harmonização das

\footnotetext{
${ }^{3}$ Em 1996, com a aprovação da nova Lei Agrícola nos Estados Unidos, altera-se o padrão de política agrícola até então adotado naquele país. A ênfase na garantia de preços, controle da oferta através da restrição da área cultivada e formação de estoques passa a ser substituida por maior flexibilidade no plantio, novas medidas de crédito e seguro agrícola, preservação ambiental e apoio às exportações de produtos agrícolas. Segundo diversos autores, o objetivo da Lei Agrícola foi garantir créditos e subsídios às vendas ao exterior e desenvolver novos mercados.
} 
políticas -setoriais; os riscos e oportunidades com a criação do esquema de integração regional, a distribuição dos ganhos e perdas associados ao processo.

São ainda poucos os estudos que analisam os impactos da liberalização comercial entre os países do hemisfério ocidental sobre o setor agrícola na região. Lee (1995) aponta que as barreiras tarifárias já vêm declinando substancialmente na região nos últimos dez anos, assim como as barreiras não-tarifárias têm sido reduzidas ou eliminadas. $O$ autor identifica que entre os subsetores da agricultura que deverão mais se beneficiar com o processo estão os subsetores de grãos na Argentina e nos Estados Unidos, e os subsetores de frutas e vegetais no Brasil, Chile e México.

No entanto, Coutinho e Furtado (1998) indicam que uma das áreas mais problemáticas do processo de integração é a agricultura. Sugerem que "avançar na integração significa reconhecer que não apenas as barreiras comerciais devem ser removidas, mas devem também sê-lo as práticas que distorcem os preços e as condições de concorrência. No que se refere aos produtos agrícolas, isto envolve principalmente os subsídios" (p. 45). Os Estados Unidos alegam que seus subsídios dependem da existência de subsídios em países que não farão parte da ALCA, implicando que as negociações para a formação da área de livre comércio devam ser articuladas com as negociações multilaterais em curso, no âmbito da OMC.

Nas negociações agrícolas para a formação da ALCA, Lopes (1997) sugere que "as alternativas são muito estreitas e não adianta criar expectativas muito ambiciosas" (p. 7). Indica que, para compensar os subsídios outorgados pelos países desenvolvidos a produtos sensíveis ao interesse brasileiro, podese negociar o acesso limitado destes produtos aos mercados domésticos e impor direitos compensatórios para contra-arrestar tais práticas.

Waquil (1998) analisa os impactos de diferentes cenários de integração regional sobre o setor de grãos, dando atenção especial para as preocupações que os países do MERCOSUL têm demonstrado com relação à formação da ALCA e de um acordo comercial do MERCOSUL com a UE. Indica que, apesar dos países desenvolvidos aceitarem discutir a questão dos subsídios agrícolas, ainda não existe uma disposição clara por parte destes países de aprofundamento da liberalização e de acesso aos seus mercados. Utilizando um modelo de alocação espacial, o autor apresenta mensurações dos efeitos da liberalização comercial sobre os níveis de produção, consumo, fluxos comerciais e preços. Aponta que a formação da ALCA não possibilita ganhos pela abertura de novos mercados para os países do MERCOSUL, mas facilita o acesso dos exportadores canadenses e americanos principalmente ao mercado brasileiro. Com isto, tanto os produtores de grãos brasileiros como os argentinos têm perdas com o processo de liberalização, basicamente em função das 
assimetrias e das distorções existentes nos mercados. Conclui que, do ponto de vista dos produtores de grãos nos países do MERCOSUL, o cenário de um acordo com a UE seria mais benéfico do que a formação da ALCA, apontando então para a adoção de uma estratégia de negociação multilateral, discutindo acordos com outros blocos paralelamente às negociações da ALCA.

Da mesma forma - conforme já citado anteriormente --, Pereira (1997) conclui que o acordo entre o MERCOSUL e a UE seria mais vantajoso para $o$ Brasil do que a formação da ALCA. A autora aponta que o acordo com a UE tenderia a aumentar as exportações brasileiras de produtos agropecuários (chegando a $+446 \%$ para grãos, $+273 \%$ para outros produtos vegetais, e $+334 \%$ para produtos animais), enquanto a criação da ALCA elevaria as exportações brasileiras de produtos manufaturados para os Estados Unidos e Canadá, mas as exportações de produtos agrícolas teriam um comportamento bem distinto ( $-1 \%$ para grãos, $-2 \%$ para outros produtos animais, mas $+67 \%$ para produtos animais). Por outro lado, a autora cita que as importações brasileiras também sofreriam impactos diferenciados: estes fluxos comerciais de produtos agrícolas aumentariam de forma moderada, mas na hipótese da formação da ALCA aumentariam mais as importações de bens que concorrem com os produzidos domesticamente, enquanto na hipótese de um acordo com a UE aumentariam mais as importações de bens que contam com maior complementaridade com a produção doméstica.

Valverde e Teixeira (1997) indicam também que a implantação da ALCA favorece o setor de grãos do Canadá e Estados Unidos, com ligeiros aumentos nas quantidades produzidas e exportadas, enquanto prejudicam o setor de grãos no Brasil e México, reduzindo as quantidades produzidas e aumentado as quantidades importadas. Entretanto, apontam que, embora o Brasil apresente perdas na produção de grãos, há ganhos na produção de outros produtos vegetais (café, açúcar), produtos animais, florestais, minerais, produtos da indústria alimentícia, bebidas e fumo. De forma distinta dos outros estudos, Valverde e Teixeira (1997) sugerem que o Brasil é o maior beneficiado com a formação da ALCA no que se refere à balança comercial, enquanto os Estados Unidos e a UE são os maiores prejudicados.

Por fim, Taglialegna, Jank, Miranda e Ribeiro (1998) indicam que o Brasil tem apresentado déficit na balança comercial agroindustrial com os países do MERCOSUL, assim como com os países da ALCA. O superávit obtido no saldo da balança comercial agroindustrial total surge basicamente das relações comerciais com a UE, levando então à necessidade de maior detalhamento e cautela nas negociações para a formação da ALCA. 


\section{Conclusão}

A caracterização do setor agrícola dos países que formarão a ALCA permite identificar diversas assimetrias. Existem também distorções nos mercados, causadas por diferentes políticas de apoio ao setor, principalmente pela ocorrência de subsídios à produção e às exportações agrícolas, e por barreiras ao acesso aos mercados na região. A implantação da área de livre comércio, apenas eliminando as barreiras ao comércio, certamente não é suficiente para gerar benefícios a todos os atores neste cenário.

Os resultados apresentados para o setor agrícola apontam na mesma direção dos resultados para as economias como um todo: há a possibilidade de polarização e de distribuição desigual dos benefícios e dos custos, entre as nações participantes e entre os subsetores da agricultura nestas nações. Tendo em vista as condições atuais, a maior parte dos estudos indicam perdas associadas ao processo de integração comercial maiores que os ganhos para o Brasil, implicando a necessidade de ajustamentos, de preparação, de obtenção de condições iguais de competição. Para os países do MERCOSUL, as negociações para a formação da ALCA não devem impedir acordos comerciais com a UE e com os países asiáticos, os quais tendem a gerar maiores ganhos para o setor agrícola do bloco do Cone Sul, em vista das relações de complementaridade existentes.

Para que os benefícios sejam percebidos por todos os integrantes, dando sustentação ao processo, é importante priorizar o setor agrícola nas negociações, implementar as medidas acordadas na Rodada Uruguai do GATT, aprofundando-as no âmbito da OMC. É necessário também discutir e coordenar políticas setoriais e macroeconômicas, eliminar distorções nos mercados, estabelecer objetivos comuns, priorizar as condições de desenvolvimento das menores economias da região e dar assistência especial aos agricultores de baixa renda. É fundamental atuar conjuntamente com os parceiros do MERCOSUL e com os demais países latino-americanos nas negociações para a formação da ALCA, evitando que a iniciativa seja simplesmente a consolidação da influência dos Estados Unidos na região, e assim visando reduzir os desequilíbrios sociais hoje existentes. 


\section{Referências bibliográficas}

ARAÚJO Jr., José T. ALCA: riscos e oportunidades para o Brasil. Trabalho apresentado no Seminário ALCA: riscos e oportunidades para o Brasil. Rio de Janeiro, São Paulo: IPRI, 1998 (documento coletado via internet: www.mre.gov.br/ipri).

AVERBUG, André. "O Brasil no contexto da integração hemisférica: controvérsias em torno da ALCA". Revista do BNDES, Rio de Janeiro, v.6, n.11, p.49-78, jun. 1999.

CARVALHO, Alexandre e PARENTE, Andréia. Impactos comerciais da Area de Livre Comércio das Américas. Brasília: IPEA, 1999. (Texto para discussão n. 635).

COUTINHO, Luciano e FURTADO, João. A integração continental assimétrica e acelerada: riscos e oportunidades. Trabalho apresentado no Seminário "ALCA: riscos e oportunidades para o Brasil". Rio de Janeiro, São Paulo: IPRI, 1998 (documento coletado via internet: www.mre.gov.br/ ipri).

GONÇALVES, Reinaldo. ALCA e MERCOSUL: fatos e visões. Trabalho apresentado no Seminário ALCA: riscos e oportunidades para o Brasil. Rio de Janeiro, São Paulo: IPRI, 1998 (documento coletado via internet: www.mre.gov.br/ipri).

LEE, D. Western hemisphere economic integration: implications and prospects for agricultural trade. Paper presented at the American Agricultural Economics Association (AAEA) meeting, Indianapolis, 1995.

LOPES, Mauro R. "O que o Brasil pode esperar das negociações agrícolas na ALCA". Agroanalysis, v.17, n.5, p.7-8, maio 1997.

MACADAR, B. "Política comercial brasileira: os dilemas da inserção internacional”. Ensaios FEE, v.17, n.1, p.234-52, 1996.

PEREIRA, Lia V. Análise comparativa dos ganhos de integração: ALCA e União Européia. Fundação Getúlio Vargas, 1997. (Relatório de pesquisa)

TAGLIALEGNA, Gustavo; JANK, Marcos; MIRANDA, Sílvia e RIBEIRO, Fátima. "O Brasil na ALCA: dimensões do comércio agroindustrial". Preços Agrícolas, ano 13, n.145, p.8-13, novembro 1998. 
VALVERDE, Sebastião R. e TEIXEIRA, Erly C. “'Impactos do acordo da Área de Livre Comércio das Américas (ALCA) no comércio internacional". Anais do XXXV Congresso Brasileiro de Economia e Sociologia Rural. Natal, RN: SOBER, 1997. (CD-ROM)

WAQUIL, Paulo D. "Cenários de integração regional: impactos sobre o setor produtivo de grãos no Mercosul". Anais do I Encontro de Economia e Econometria da Região Sul. Florianópolis,SC: 1998. (CD-ROM) 